\title{
METABOLISM OF D-CEPHALOGLYCIN $-{ }^{14} \mathrm{C}^{*}$ AND L-CEPHALOGLYCIN- ${ }^{14} \mathrm{C}$ IN THE RAT
}

\author{
Hugh R. Sullivan, Ruth E. Billings \\ and Robert E. McMAHON \\ The Lilly Research Laboratories, Eli Lilly and Company \\ Indianapolis, Indiana 46206 U. S. A.
}

(Received for publication November 11, 1968)

\begin{abstract}
The fate of the orally effective antibiotic D-cephaloglycin and its much less active L-enantiomer has been studied in the rat. ${ }^{D}-C e p h a l o g l y c i n-{ }^{14} \mathrm{C}$ is metabolized by two pathways, (1) hydrolysis of the amide linkage to form $\mathrm{D}-2$-phenylglycine $-{ }^{14} \mathrm{C}$ and (2) deacetylation to form deacetyl-D-cephaloglycin${ }^{14} \mathrm{C}$. $\mathrm{D}$-Cephaloglycin is absorbed from the gastro-intestinal tract at least in part as the intact antibiotic. L-Cephaloglycin ${ }^{14} \mathrm{C}$ is rapidly metabolized to $\mathrm{L}-2$-phenylglycine $-{ }^{14} \mathrm{C}$ and its metabolites. In contrast to the results with $\mathrm{D}^{-}$ cephaloglycin $-{ }^{14} \mathrm{C}$, no intact $\mathrm{L}$-cephaloglycin $-{ }^{14} \mathrm{C}$ or deacetyl-L-cephaloglycin was excreted in the urine of rats.
\end{abstract}

D-Cephaloglycin is a broad spectrum antibiotic, active against gram-positive cocci, including penicillin-resistant strains, as well as against many gram-negative organisms ${ }^{1)}$. Unlike many other members of this family of antibiotics, D-cephaloglycin is active when administered orally ${ }^{2)}$. In contrast to the $\mathrm{D}$-isomer, L-cephaloglycin shows very limited activity in in vitro tests against Staphylococcus aureus. As in previous studies on the fate of cephalosporin antibiotics from these laboratories ${ }^{3,4)}$ radiocarbon labeling has been used to facilitate the present investigation.

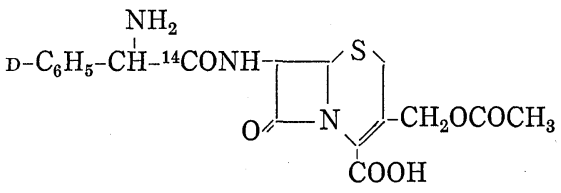

D-Cephaloglycin- ${ }^{14} \mathrm{C}$

\section{Materials and Methods}

$\mathrm{D}(-)$ and $\mathrm{L}(+)-2-\mathrm{Phen} y \operatorname{lglycine}-{ }^{14} \mathrm{C}$. The procedure used for the preparation of racemic 2-phenylglycine ${ }^{14} \mathrm{C}$ and its enzymatic resolution of its enantiomorphic forms has been described by Billings and Sullivan ${ }^{5}$.

D-Cephaloglycin $-{ }^{14} \mathrm{C}$. D-Phenylglycine $-{ }^{14} \mathrm{C}, 2.07 \mu \mathrm{c} / \mathrm{mg}$, was allowed to react with 5.0 $\mathrm{m}$-moles of methyl acetoacetate in a solution consisting of $5.0 \mathrm{~m}$-moles of sodium hydroxide, $0.35 \mathrm{ml}$ of $\mathrm{H}_{2} \mathrm{O}$ and $2.0 \mathrm{ml}$ of methanol. After heating for 30 minutes at $60^{\circ} \mathrm{C}$, the clear reaction solution was evaporated to dryness in vacuo. The residual oil was dried for 24 hours in vacuo over concentrated sulfuric acid to yield semi-solid; methyl 3-(D- $\alpha-$ carboxybenzylamino)crotonate $-{ }^{14} \mathrm{C}$ sodium salt.

Ethyl chloroformate $(8.4 \mathrm{~m}$-moles) was allowed to react with a solution consiting of

* In this paper the term $\mathrm{D}$-cephaloglycin $-{ }^{14} \mathrm{C}$ is used to designate $7-(\mathrm{D}-\alpha$-aminophenyl[1-14 $\mathrm{C}]$ acetamido)cephalosporanic acid. L-Cephaloglycin- ${ }^{14} \mathrm{C}$ will refer to 7 -( $\mathrm{L}-\alpha$-aminophenyl[1- $\left.{ }^{14} \mathrm{C}\right]$ acetamido)cephalosporanic acid. The optical isomers of $\alpha$-aminophenyl[1-14C]acetic acid will be designated as $\mathrm{D}$ - or $\mathrm{L}-2$-phenylglycine- ${ }^{14} \mathrm{C}$. 
$5 \mathrm{~m}$-moles of methyl $3-\left(\mathrm{D}-\alpha\right.$-carboxybenzylamino)crotonate $-{ }^{14} \mathrm{C}$ sodium salt in $14 \mathrm{ml}$ of acetonitrile containing one drop of $\mathrm{N}, \mathrm{N}$-dimethylbenzylamine at $-10^{\circ} \mathrm{C}$. After stirring the solution for 15 minutes at this temperature, a solution of $5 \mathrm{~m}$-moles of 7-aminocephalosporanic acid $\left.{ }^{6}\right)$ in $12 \mathrm{ml}$ of acetonitrile-water $(1: 1, \mathrm{v} / \mathrm{v})$ containing $5 \mathrm{~m}$-moles of triethylamine was added rapidly with stirring. After 30 minutes, $4.0 \mathrm{~g}$ of sodium chloride were added to the reaction mixture and stirring continued for 15 minutes at $0^{\circ} \mathrm{C}$. The organic phase was separated and evaporated to dryness in vacuo. The residual oil was dissolved in $26 \mathrm{ml}$ of isobutylmethyl ketone-water $(10: 3, \mathrm{v} / \mathrm{v})$ containing $1.5 \mathrm{ml}$ of $99 \%$ formic acid and the solution allowed to stand at $0^{\circ} \mathrm{C}$ for 18 hours to facilitate complete crystallization of the $\mathrm{D}-$ cephaloglycin $-{ }^{14} \mathrm{C}$. The product was collected by centrifugation. It was then suspended in $20 \mathrm{ml}$ of acetonitrile and reisolated by centrifugation and dried in vacuo. The yield was $487 \mathrm{mg}(24 \%)$ of pure $\mathrm{D}$-cephaloglycin- ${ }^{14} \mathrm{C}$ with a specific radioactivity of $0.6 \mu \mathrm{C} / \mathrm{mg}$. Paper chromatography followed by biological and radiological assay showed the product to be pure.

$\mathrm{L}$-Cephaloglycin $-{ }^{14} \mathrm{C}$. Using the same procedure as described above, the L-enantiomer of cephaloglycin $-{ }^{14} \mathrm{C}$ was prepared from $5 \mathrm{~m}$-moles of $\mathrm{L}-2$-phenylglycine ${ }^{-14} \mathrm{C}$ having a specific radioactivity of $23 \mu \mathrm{C} / \mathrm{mg}$. The yield of pure L-cephaloglycin- ${ }^{14} \mathrm{C}$ was $410 \mathrm{mg}(20 \%)$ and it possessed a specific radioactivity of $0.71 \mu \mathrm{C} / \mathrm{mg}$.

Chromatographic methods. Paper chromatography was carried out on Whatman No. 1 paper and a butan-1-ol-acetic acid-water ( $3: 1: 1$ by vol) solvent system was employed for development. Areas of biological activity were located by a bioautographic technique described by Miller ${ }^{i)}$ using Bacillus subtilis. The radioactive zones were located by using a scanner (Vanguard 880 Automatic Chromatogram Scanner).

Urinary, fecal and biliary excretion studies. Aqueous solutions of the enantiomorphic forms of 2-phenylglycine $-{ }^{14} \mathrm{C}$, sodium salt and of cephaloglycin ${ }^{14} \mathrm{C}$ (46 $\mu \mathrm{moles} / \mathrm{kg}$ ) were administered both by the intraperitoneal and oral routes to groups of $200 \mathrm{~g}$ male PurdueWistar rats. The rats were kept in stainless steel metabolism cages. Urine samples were collected at regular intervals (2 hours) and feces samples were collected after 24 hours.

The radioactivity contained in each urine sample was determined by liquid scintillation counting. The nature of the radiocarbon metabolites and the amount present in the urine was determined by paper chromatographic analysis of each sample. The biologically active metabolites were identified by comparison chromatography using authentic samples of cephaloglycin and deacetylcephaloglycin.

Feces samples were dried, ground and analyzed for radiocarbon content by the SchöNIGER combustion method described by KeLLy et al ${ }^{8)}$.

For the bile study, $200 \mathrm{~g}$ male rats were anesthetized with ether and a cannula placed in the common bile duct. The $\mathrm{D}$-cephaloglycin- ${ }^{14} \mathrm{C}$ was adminitered orally and the bile fluid collected for 24 hours. Radiocarbon content was determined by liquid scintillation counting of an aliquot of the bile fluid.

Blood level studies. An aqueous solution of $\mathrm{D}$-cephaloglycin- ${ }^{14} \mathrm{C}$ was administered intraperitoneally and orally to $200 \mathrm{~g}$ male Purdue-Wistar rats at a dose rate of $46 \mu \mathrm{moles} /$ $\mathrm{kg}$. At given time intervals blood samples were removed from the tail vein. The samples, averaging $200 \mathrm{mg}$ in weight, were placed in sausage-casing bags, dried for 48 hours and the radiocarbon content of each was determined by the SchöNIGER combustion method.

\section{Results and Discussion}

The presence of penicillin amidases or deacylating enzymes among fungi, yeasts and bacteria is well known ${ }^{9,10,11)}$. These enzymes catalyze the hydrolysis of the sidechain amide moiety of many penicillins to yield the corresponding carboxylic acid and 6-amino-penicillanic acid. These enzymes show similar activity towards certain cephalosporin antibiotics ${ }^{12,13,14)}$. Furthermore, the hydrolysis of the side-chain amide moiety of 
several cephalosporins in vivo in the rat has been demonstrated ${ }^{3,4,15)}$. It would be reasonable to assume, that the in vivo metabolism of $\mathrm{D}$-cephaloglycin $-{ }^{14} \mathrm{C}$ and its $\mathrm{L}-$ enantiomer would involve in part the hydrolytic cleavage of the amide bond producing the corresponding optically active 2-phenylglycine- ${ }^{14} \mathrm{C}$.

Previous investigations on the metabolism of the enantiomers of 2-phenylglycine ${ }^{16,17)}$ leave some doubt as to the metabolic fate of these amino acids in the rat. A study of the metabolic fate of the isomers of 2-phenylglycine $-{ }^{14} \mathrm{C}$ in the rat was therefore carried out before work with the labeled antibiotics began.

$$
\text { D-2-Phenylglycine- }{ }^{14} \mathrm{C}
$$

Twenty-four hours after the intraperitoneal administration to rats of $\mathrm{D}-2$-phenylglycine $-{ }^{14} \mathrm{C}$, sodium salt $(40 \mathrm{mg} / \mathrm{kg}), 79 \%$ of the administered radiocarbon was recovered in the urine. Separation and identification of the radioactive metabolites by paper chromatography showed that $50 \%$ of the administered dose appeared in the urine as unaltered $\mathrm{D}-2$-phenylglycine $-{ }^{14} \mathrm{C}, 27 \%$ as benzoylformic acid- ${ }^{-14} \mathrm{C}$ and $2.0 \%$ as mandelic acid $-{ }^{14} \mathrm{C}$ (Table 1).

The total recovery of radiocarbon and the distribution of metabolites 24 hours after the oral administration of $40 \mathrm{mg} / \mathrm{kg}$ of $\mathrm{D}-2$-phenylglycine- ${ }^{14} \mathrm{C}$ was very similar to. those obtained after intraperitoneal administration. The total recovery of radiocarbon in the urine accouted for $71 \%$ of the administered dose. Unchanged D-phenylglycine${ }^{14} \mathrm{C}$ again was the major metabolite representing $41 \%$ of the administered dose. Benzoylformic aeid- ${ }^{14} \mathrm{C}$ was the other major metabolite representing $30 \%$ of the administered radiocarbon.

\section{L-2-Phenylglycine- ${ }^{14} \mathrm{C}$}

Table 1 also shows the total radiocarbon recovered and the distribution of labeled metabolites 24 hours following an intraperitoneal administration of $40 \mathrm{mg} / \mathrm{kg}$ of L-2phenylglycine $-{ }^{14} \mathrm{C}$. These results show that $89 \%$ of the administered radiocarbon was. recovered in the urine of rats. Benzoylformic acid- ${ }^{14} \mathrm{C}$ was the major metabolite accounting for $83.5 \%$ of the administered dose. Trace amounts of mandelic acid- ${ }^{14} \mathrm{G}$. $(3.7 \%)$ and unchanged $\mathrm{L}-2$-phenylglycine $-{ }^{14} \mathrm{C}(1.8 \%)$ could be detected.

Oral administration of the $\mathrm{L}-2-$ phenylglycine $-{ }^{14} \mathrm{C}$ gave similar results. The total urinary radiocarbon amounted to $77 \%$ of the administered dose and benzoylformic acid- ${ }^{14} \mathrm{C}$ again was the major radioactive metabolite representing $74.5 \%$ of the admini-

Table 1. Total urinary radioactivity (RA) and distribution of urinary metabolites following oral and intraperitoneal administration of the optical isomers of 2 -phenylglycine- ${ }^{14} \mathrm{C} *$

\begin{tabular}{c|l|r|r|r|r}
\hline \multirow{2}{*}{} & \multicolumn{3}{|c}{ Enantiomer } \\
\cline { 2 - 5 } & \multicolumn{2}{|c}{$\mathrm{L}(+)$} & \multicolumn{2}{c}{$\mathrm{D}(-)$} \\
\cline { 2 - 5 } & Oral & I.P. & Oral & I.P. \\
\hline \multirow{2}{*}{ Total urinary RA } & 77 & 89 & 71 & 79 \\
\hline \multirow{2}{*}{ Metabolites } & 2-Phenylglycine-14C & 0 & 1.8 & 41 & 50 \\
& Mandelic acid-14 C & 2.5 & 3.7 & 0 & 2 \\
& Benzoylformic acid-14C & 74.5 & 83.5 & 30 & 27 \\
\hline
\end{tabular}

\footnotetext{
* Results expressed in terms of $\%$ of radioactive dose.
} 
stered dose. A trace amount of mandelic acid- ${ }^{14} \mathrm{C}(2.5 \%)$ could be detected.

The results of this metabolism study showed first that oxidative deamination, as suggested by NEUBAUER ${ }^{16)}$, was the major mechanism involved in the metabolism of the enatiomers of 2-phenylglycine- $-{ }^{14} \mathrm{C}$. The mandelic acid- ${ }^{14} \mathrm{C}$ isolated probably resulted from a small amount of enzymatic reduction of the deamination product, benzoylformic acid- ${ }^{14} \mathrm{C}$. It is well known that mandelic acid is relatively stable in vivo and is largely excreted unchanged ${ }^{18}$.

Secondly there is a distinct difference in the metabolic stabilities of the enantiomers of this amino acid in the body. Thus the $\mathrm{L}(+)$ isomer is much more readily deaminated to benzoylformic acid than the $\mathrm{D}(-)$ isomer.

With the basic information available on the fate of the isomers of phenylglycine it now became possible to proceed with a study of the metabolism of the isomers of cephaloglycin.

\section{Excretion Studies}

D-Cephaloglycin- ${ }^{14} \mathrm{C}$. Fig. 1 shows the recovery of total urinary radioactivity as well as the distribution of radioactive metabolites in the urine following a single orally administered dose of $\mathrm{D}$-cephaloglycin ${ }^{14} \mathrm{C}$ to rats. Four percent of the administered radiocarbon had appeared in the urine after 4 hours, $12 \%$ in 12 hours and $20 \%$ in 24 hours. The feces collected over this 24 -hour period were found to contain $70 \%$ of the administered dose. Cannulation of the bile duct prior to the administration of a single dose of $\mathrm{D}$-cephaloglycin- ${ }^{14} \mathrm{C}$ and subsequent collection of a 24-hour sample of the bile fluid revealed that $8 \%$ of the administered radiocarbon was eliminated by this route. Thus, most of the radioactivity appearing in the feces probably represents the drug or its degradation products.

The separation of the radioactive metabolites in each urine sample was accomplished by use of paper chromatographic techniques. One biologically active metabolite was found in the urine and this was found during the first 8 hours. This metabolite was identified as deacetylcephaloglycin ${ }^{14} \mathrm{C}$ and it represented $2 \%$ of the administered dose. In addition to this metabolite, paper chromatography indicated the presence of four biologically inactive metabolites. The major metabolites were 2-phenylglycine $-{ }^{14} \mathrm{C}, 8.5 \%$ of the administered dose, and benzoylformic acid- ${ }^{14} \mathrm{C}, 5.0 \%$. The minor metabolites were mandelic $\operatorname{acid}-{ }^{14} \mathrm{C}, 1.5 \%$, and an unidentified polar metabolite, $3.0 \%$.

Oral administration of large doses $(200 \mathrm{mg} / \mathrm{kg})$ of $\mathrm{D}$-cephaloglycin $-{ }^{14} \mathrm{C}$ caused increased amounts of the deacetylcephaloglycin $-{ }^{14} \mathrm{C}$ to be found in the urine. In

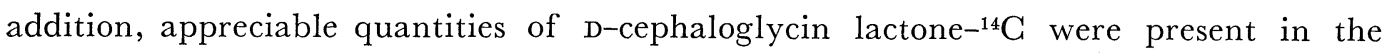
urine. Small amounts of unchanged $\mathrm{D}$-cephaloglycin $-{ }^{14} \mathrm{C}$ were also found in the urine, thus demonstrating that this antibiotic is absorbed, at least in part, in unchanged form.

The distribution of urinary metabolites following oral administration of $\mathrm{D}$-cepha$\log l y c i n-{ }^{14} \mathrm{C}$, with the exception of a small amount of deacetylcephaloglycin ${ }^{14} \mathrm{C}$ and an unknown polar metabolite, was very similar to that obtained after oral dosage of the $\mathrm{D}-2$-phenylglycine $-{ }^{14} \mathrm{C}$. Thus the urinary metabolites obtained resulted, for the most part, from the metabolism of 2 -phenylglycine $-{ }^{14} \mathrm{C}$, the product of the enzymatic 
Fig. 1. Total radioactivity and the distribution of radioactive metabolites in the urine of rats after oral administration of $\mathrm{D}$-cephaloglycin${ }^{14} \mathrm{C}$.

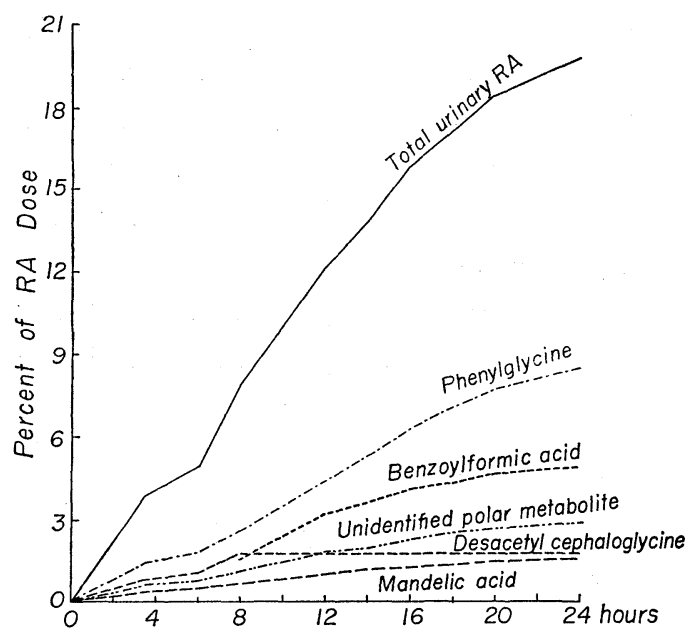

Fig. 2. Total radioactivity and the distribution of radioactive metabolites in the urine of rats after intraperitoneal administration of D-cephaloglycin ${ }^{14} \mathrm{C}$.

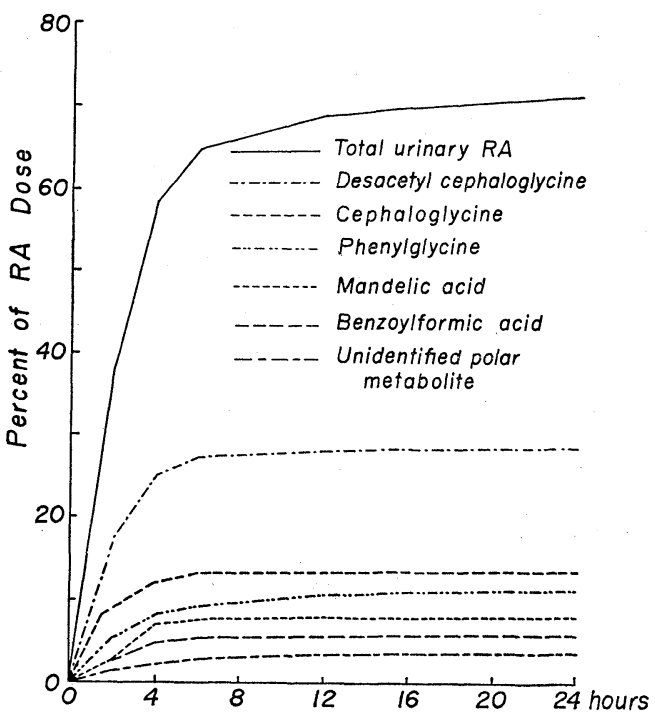

hydrolysis of the side-chain amide moiety of the antibiotic.

The total urinary radioactivity and distribution of radioactive metabolites after intraperitoneal administration of a single dose of $\mathrm{D}$-cephaloglycin ${ }^{14} \mathrm{C}$ to rats is shown in Fig. 2. The recovery of radiocarbon in the urine was, as expected, much greater than that obtained after oral administration. After 1 hour, $38 \%$ of the administered radioactivity had appeared in the urine, $59 \%$ after 4 hours and $71 \%$ after 24 hours. The major radioactive metabolites identified were the unchanged $\mathrm{D}$-cephaloglycin $-{ }^{14} \mathrm{C}$ (13.5\% of the administered radiocarbon) and $\mathrm{D}$-deacetylcephaloglycin ${ }^{14} \mathrm{C}(28.6 \%)$. Other biologically inactive metabolites were: $\mathrm{D}-2$-phenylglycine $-{ }^{14} \mathrm{C}(11.3 \%)$, benzoylformic acid- ${ }^{14} \mathrm{C}(7.8 \%)$, mandelic $\operatorname{acid}-{ }^{14} \mathrm{C}(6.0 \%)$ and an unknown ${ }^{14} \mathrm{C}$-labeled polar metabolite $(3.8 \%)$.

These results show that parenterally administered $\mathrm{D}$-cephaloglycin is metabolized mainly by deacetylation to deacetylcephaloglycin. Some enzymatic hydrolysis of the 2-phenylglycine moiety did occur, however, as shown by the excretion of benzoylformic acid, 2-phenylglycine and mandelic acid.

$\mathrm{L}$-Cephaloglycin ${ }^{14} \mathrm{C}$. When this relatively inactive enantiomer of $\mathrm{D}$-cephaloglycin${ }^{14} \mathrm{C}$ was administered intraperitoneally to rats, the excretion of metabolites was rapid (Fig. 3). Sixty-five percent of the administered radioactivity had appeared in the urine during the first 4 hours and $71 \%$ after 12 hours. Unlike its biologically active enantiomer, L-cephaloglycin- ${ }^{14} \mathrm{C}$ was rapidly metabolized in vivo. No evidence for the presence of unchanged antibiotic or its deacetyl derivative could be found in the urine. The ${ }^{14} \mathrm{C}$-labeled metabolites present in the urine were identified as : benzoylformic acid $(75.5 \%)$, mandelic acid $(9.1 \%)$, L-2-phenylglycine $(6.2 \%)$, and an unidentified polar metabolite $(9.2 \%)$. This distribution of metabolites was reminiscent of that obtained earlier from the metabolism study of $\mathrm{L}-2-$ phenylglycine $-{ }^{14} \mathrm{C}$. These results 
showed that the major route of metabolism of $\mathrm{L}$-cephaloglycin- ${ }^{14} \mathrm{C}$ was by enzymatic hydrolysis of the side-chain amide grouping to produce $\mathrm{L}-2$-phenylglycine $-{ }^{14} \mathrm{C}$ as the primary labeled metabolite.

After oral administration of $\mathrm{L}$-cephaloglycin $-{ }^{14} \mathrm{C}$ to rats, $58 \%$ of the administered radiocarbon was found in the urine after 24 hours. Like the intraperitoneal study no unchanged antibiotic or its deacetyl derivative could be found in the urine. The distribution of ${ }^{14} \mathrm{C}$-labeled metabolites, i.e. benzoylformic acid (74.0\%), mandelic acid $(6.0 \%), 2$-phenylglycine $(6.0 \%)$ and an unidentified polar metabolite $(14.0 \%)$, was similar to the distribution of metabolites obtained from the urine of rats after oral or intraperitoneal administration of $\mathrm{L}-2$-phenylglycine $-{ }^{14} \mathrm{C}$.

These results can be interpreted to mean that the L-cephaloglycin is substantially more sensitive to enzymatic hydrolysis than is $\mathrm{D}$-cephaloglycin. This may explain its lack of microbiological activity.

Fig. 3. Total radioactivity and the distribution of radioactive metabolites in the urine of rats after intraperitoneal administration of $\mathrm{L}^{-}$-cephaloglycin- ${ }^{14} \mathrm{C}$.

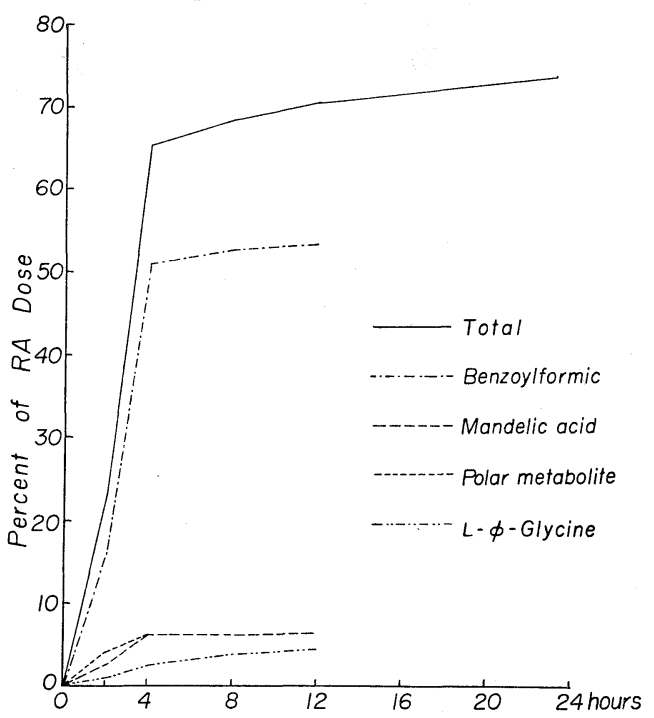

Fig. 4. Whole blood radiocarbon levels in rats after oral and intraperitoneal administration of $\mathrm{D}$-cephaloglycin- ${ }^{14} \mathrm{C}$.

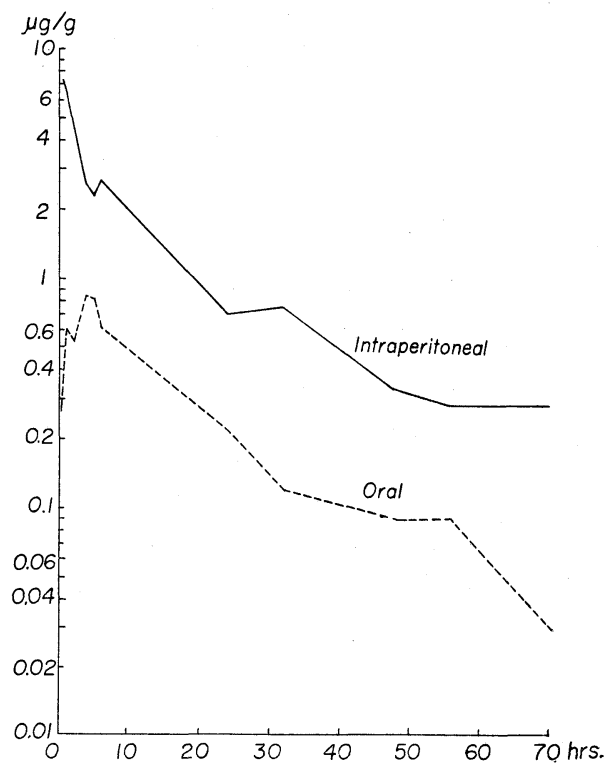

Whole Blood Radiocarbon Levels

The radiocarbon blood level curves obtained after intraperitoneal and oral administration of $46 \mu$ moles $/ \mathrm{kg}$ of $\mathrm{D}$-cephaloglycin- ${ }^{14} \mathrm{C}$ to rats are shown in Fig. 4. Thirty minutes after intraperitoneal administration maximum radiocarbon levels equivalent to $7.5 \mu \mathrm{g}$ of antibiotic per milliliter of blood were obtained. Radiocarbon levels declined with a half-life of approximately $2 \sim 3$ hours. Since the half-life of the parent drug appears to be extremely short it is reasonable to assume that most of the radiocarbon in the blood is in the form of deacetyl-D-cephaloglycin. The measured half-life of $2 \sim 3$ hours is assumed to be the half-life of deacetyl-D-cephaloglycin. The peak blood level found 4 hours after oral administration of the antibiotic was much lower $(0.85 \mu \mathrm{g} / \mathrm{g}$ of blood). The radiocarbon curves were bimodal in character 
indicating the presence of a longer half-lived ${ }^{14} \mathrm{C}$-labeled metabolite in the blood. The level of this long-lived cephaloglycin ${ }^{14} \mathrm{C}$ metabolite was quite low representing in this instance less than $0.1 \%$ of the radioactive dose. Its half-life was of the order of 24 hours. The nature of this long-lived trace metabolite is unknown.

\section{Ref erences}

1) WICK, W. E. \& W. S. BonIECE : In vitro and in vivo laboratory evaluation of cephaloglycin and cephaloridine. Appl. Microbiol. $13: 248 \sim 253,1965$

2) Spencer, J. L.; E. H. Flynn, R. W. Roeske, F. Y. Siu \& R. R. Chauvette : Chemistry of cephalosporin antibiotics. VII. Synthesis of cephaloglycin and some homologs. J. Med. Chem. 9 : $746 \sim 750,1966$

3) Sullivan, H. R. \& R. E. McMahon : Metabolism of oral cephalothin and related cephalosporins in the rat. Biochem. J. $102: 976 \sim 982,1967$

4) Culp, H. W.; F. J. Marshall \& R. E. McMahon : Metabolism and absorption of 7-(phenylacetamido-1-C14)-cephalosporanic acid. Antimicr. Agents \& Chemoth. $1963: 243 \sim 246,1964$

5) Billings, R. \& H. R. Sullivan : Synthesis and enzymatic resolution of DL-2-phenylglycine-1${ }^{14} \mathrm{C}$. J. Label. Compounds $3: 17 \sim 19,1967$

6) Morin, R. B.; B. G. JACkson, E. H. FlynN \& R. W. Roeske : Chemistry of cephalosporin antibiotics. I. 7-Aminocephalosporanic acid from cephalosporin C. J. Am. Chem. Soc. $84: 3400 \sim$ 3401, 1962

7) Miller, R. P. : A paper chromatographic assay for cephalosporins. Antibiot. \& Chemoth. 12 : $689 \sim 693,1962$

8) Kelly, R. G.; E. A. Peets, S. Gordon \& D. A. Buyske : Determination of $\mathrm{C}^{14}$ and $\mathrm{H}^{3}$ in biological samples by Schöniger combustion and liquid scintillation techniques. Anal. Biochem. 2 : $267 \sim 273,1961$

9) Claridge, C. A.; J. R. Luttinger \& J. Lein : Specificity of penicillin amidases. Proc. Soc. Exp. Biol. \& Med. $113: 1008 \sim 1012,1963$

10) Cole, M. : Formation of 6-aminopenicillanic acid, penicillins, and penicillin acylase by various fungi. Appl. Microbiol. $14: 98 \sim 104,1966$

11) Huang, H. T.; A. R. English, T. A. Seto, G. M. Shull \& B. A. Sobin : Enzymatic hydrolysis of the side chain of penicillins. J. Am. Chem. Soc. $82: 3790 \sim 3791,1960$

12) Huang, H. T.; T. A. Seto \& G. M. Shull : Distribution and substrate specificity of benzylpenicillin acylase. Appl. Microbiol. $11: 1 \sim 6,1963$

13) Holt, R. J. \& G. T. Stewart : Production of amidase and $\beta$-lactamase by bacteria. J. Gen. Microb. $36: 203 \sim 213,1964$

14) Sjöberg, B.; L. Nathorst-Westfelt \& B. Örtengren : Enzymatic hydroylsis of some penicillins and cephalosporins by Escherichia coli acylase. Acta Chem. Scand. $21: 547 \sim 551,1967$

15) Okui, M.; K. Hatтori \& M. Nishida: Studies on the metabolism of cephalosporins. I. The distribution and degradation of $7-\left[\left(1-{ }^{14} \mathrm{C}\right)-3\right.$-chlorophenyl-acetamido]-cephalosporanic acid. J. Antibiotics, Ser. A $20: 287 \sim 292,1967$

16) Neubauer, O.: Decomposition of amino acids in well and diseased organisms. Deut. Arch. Klin. Med. $95: 211 \sim 256,1909$

17) Montenbruck, D. : Degradation of $\alpha$-amino acids. Behavior of mandelic acid in the human organism. Arch. Exp. Pathol. Pharmakol. 195 : 164 174, 1940

18) Williams, R. T. : Detoxication Mechanisms. p. 380, New York, John Wiley and Sons, Inc., 1959 